Psicologia Escolar

e Educacional
ARTIGO

DOI: http://dx.doi.org/10.1590/2175-35392022225431

Localizador - e225431

\title{
A ARTE NA (RE)CONSTRUÇÃO DA IDENTIDADE DE ADOLESCENTES EM UMA ESCOLA DO CAMPO
}

\author{
Elizabeth Antônia Leonel de Moraes Martines ${ }^{1} \mathbb{D}$; Suzana Rocha de Souza Azevedo ${ }^{2} \mathbb{D}$; Maria Isabel da Silva Leme ${ }^{3} \mathbb{D}$
}

\section{RESUMO}

Este trabalho é parte de uma pesquisa que problematizou a construção da identidade do adolescente em processo de escolarização e sua relação com o ensino de Arte. Seu objetivo foi compreender a influência da Arte na construção da identidade de adolescentes em uma escola do campo, através de uma pesquisa qualitativa com doze adolescentes do $6^{\circ}$ ao $9^{\circ}$ ano que participaram de cinco encontros de vivências artísticas filmadas, com uso de observação participante, registros ampliados e entrevistas. A Psicologia Cultural evidenciou a importância da escola no desenvolvimento da atividade criadora e do ensino da Arte na (re)construção da identidade dos adolescentes, contribuindo para a simbolização de experiências e sentimentos difíceis de serem expressos, como situações de bullying, perdas e lutos, diferenças de gênero e sexualidade. A interpretação das produções artísticas utilizadas constituiu-se em importante instrumento psicológico para lidar com emoções, refletindo-se no desenvolvimento de funções psicológicas superiores.

Palavras-chave: adolescência; arte; identidade

\section{Art in the (re)construction of the adolescents' identity in a rural school}

\begin{abstract}
This work is part of a research that problematizes the construction of the adolescent's identity in the schooling process and its relationship with the teaching of Art. Its objective was to understand the influence of Art in the construction of the adolescents' identity in a rural school, through a qualitative research with twelve adolescents from 6th to 9th grade who participated in five meetings of filmed artistic experiences, using participant observation, expanded records and interviews. Cultural Psychology highlighted the importance of the school in the development of creative activity and the teaching of Art in the (re)construction of the adolescents' identity, contributing to the symbolization of experiences and feelings that are difficult to express, such as situations of bullying, loss and grief, gender and sexuality differences. The interpretation of the artistic productions used was an important psychological tool to deal with emotions, reflecting about the development of higher psychological functions.
\end{abstract}

Keywords: adolescence; art; identity

\section{El arte en la (re)construcción de la identidad de adolescentes en una escuela del campo}

\section{RESUMEN}

Este estudio es parte de una investigación que problematizó la construcción de la identidad del adolescente en proceso de escolarización y su relación con la enseñanza de Arte. Su objetivo fue comprender la influencia del Arte en la construcción de la identidad de adolescentes en una escuela del campo, por intermedio de una investigación cualitativa con doce adolescentes del $6^{\circ}$ al $9^{\circ}$ curso que participaron de cinco encuentros de vivencias artísticas filmadas, con uso de observación participante, registros ampliados y entrevistas. La Psicología Cultural evidenció la importancia de la escuela en el desarrollo de la actividad creadora y de la enseñanza del Arte en la (re)construcción de la identidad de los adolescentes, contribuyendo a la simbolización de experiencias y sentimientos difíciles de ser expresos, como situaciones de bullying, pérdidas y lutos, diferencias de género y sexualidad. La interpretación de las producciones artísticas utilizadas se constituyó en importante instrumento psicológico para lidiar con emociones, reflejándose en el desarrollo de funciones psicológicas superiores.

Palabras clave: adolescencia; arte; identidad

\footnotetext{
${ }^{1}$ Universidade Federal de Rondônia (UNIR) - Porto Velho - Rondônia - RO - Brasil; bethmartines@gmail.com

2 Instituto Federal de Educação, Ciência e Tecnologia de Rondônia (IFRO) - Porto Velho - Rondônia - RO - Brasil; suzanamusica@ gmail.com

${ }^{3}$ Universidade de São Paulo - São Paulo - São Paulo - SP - Brasil; belleme@usp.br
} 


\section{INTRODUÇÃO}

Este trabalho se insere na intersecção de várias temáticas, algumas delas já analisadas em trabalho recente (Souza, Martines, \& Barroco, 2018), sendo que aqui exploramos o processo de construção narrativa da identidade em adolescentes. Neste trabalho adota-se o seguinte conceito de adolescência: "A adolescência não é um período de conclusão, mas de crise e amadurecimento do pensamento. No que tange à forma superior de pensamento, acessível à mente humana, essa idade é também transitória, e o é em todos os outros sentidos." (Vygotsky, 2001, p. 229).

Essa concepção busca superar visões em que predominam o determinismo biológico e o olhar naturalizante, que reduzem a adolescência a uma fase do desenvolvimento, sem considerar aspectos socioculturais e históricos. Vygotsky (2001) considera essa fase como um período de desenvolvimento psicológico que inclui crises e saltos qualitativos, uma idade de transição em que as funções psicológicas superiores se desenvolvem por meio da apropriação de conceitos científicos, bem como da participação no processo cultural e histórico da humanidade.

A Psicologia Cultural ${ }^{1}$ proposta por Bruner (1996/2001; 1990/2002) compartilha dessa concepção e destaca a importância da escolarização na construção do self: "Talvez o fato mais universal sobre a experiência humana seja o fenômeno do self, e nós sabemos que a educação é crucial para sua formação." (Bruner, 1996/2001, p. 40).

Para a Psicologia Cultural, a habilidade da construção e da compreensão narrativa é o caminho para a construção das nossas vidas, das nossas identidades, ou seja, dos nossos si-mesmos, a fim de encontrarmos um lugar significativo no mundo. Sendo assim, a Psicologia Cultural coloca duas exigências ao estudo do si mesmo: por um lado, que tais estudos devem focalizar os significados em que o si-mesmo é definido tanto pelo indivíduo como pela cultura da qual ele faz parte; e por outro, quais as práticas nas quais "os significados do si-mesmo" são colocados em uso. (Bruner, 1990/2002, p. 100-1). A revisão de teses e dissertações evidenciou

\footnotetext{
${ }^{1}$ Neste trabalho utilizamos conceitos de Bruner e Vigotski como referencial teórico, reconhecendo que esses autores representam duas abordagens da Psicologia, com pressupostos epistemológicos e abordagem metodológica específicos, tal como explicita, por exemplo, Rabatini na dissertação "A concepção de cultura em Bruner e Vigotski: Implicações para a educação escolar" (disponível em <https://repositorio.unesp. br/bitstream/handle/11449/92407/rabatini_vg_me_arafcl. pdf? sequence=1\&isAllowed=y>). Entretanto, entendemos que Bruner desenvolveu uma compreensão do papel da linguagem no desenvolvimento psicológico a partir do trabalho iniciado pelo russo e seus colaboradores, principalmente apoiando-se no avanço das pesquisas em linguística literária que se deram após a morte de Vigotski.
}

poucos trabalhos no Brasil que relacionam a construção de identidade e o/a adolescente em processo de escolarização, embora essa seja uma área de estudos que tem apresentado grande desenvolvimento em outros países (Vieira \& Henriques, 2014).

Dada a relevância social da compreensão de como se constitui a identidade de nossos adolescentes em processo de escolarização, entendemos a necessidade de estudos e pesquisas que relacionem esta temática com as áreas de conhecimento do currículo escolar.

Bruner (1996/2001) considera uma das principais funções da escola o desenvolvimento da habilidade de interpretação e a Psicologia Cultural que ele propôs é francamente interpretativa, sendo que sua aplicação à educação tem um princípio básico: o preceito da perspectiva. Segundo este preceito, a produção de significado de qualquer fato, proposição ou encontro é relativo à perspectiva ou quadro de referência a partir do qual é construído. "Entender bem o que algo 'significa' exige uma certa consciência dos significados alternativos que podem ser atribuídos à questão que está sendo examinada, não importando se se concorda com ela ou não" (Bruner, 1996/2001, p. 24).

Ele ressalta o "lado interpretativo, de produção de significado do pensamento humano" e "do poder de uma cultura de se adaptar à mudança, e no mundo contemporâneo, a mudança é a norma" (Bruner, 1996/2001, p. 25). Assim, promover interpretações de significados que realcem diferentes perspectivas revelam "[...] histórias idiossincráticas, mas também as formas canônicas da cultura de construir realidades"(p. 24).

Desenvolver habilidades interpretativas, sob diferentes pontos de vista ou perspectivas, auxilia crianças e jovens, bem como os professores, a construir histórias sobre si mesmos, sobre as instituições em que se formam (família, escola, igreja, por exemplo) ou atuam, vislumbrando possibilidades de mudanças e de atuação.

Ao associar esse preceito com o preceito narrativo, Bruner lembra que os psicanalistas agora reconhecem que a personalidade implica a narrativa, que a "neurose" é um reflexo de uma história insuficiente, incompleta ou imprópria que um indivíduo tem de si.

\section{Lembre-se de que quando Peter Pan pede a Wendy para voltar para a Terra do Nunca com ele, ele dá como seus motivos o fato de que ela poderia ensinar os Meninos Perdidos de lá a contar histórias. Se eles soubessem contá-las, eles poderiam crescer. (Bruner, 1996/2001, p. 44).}

Essa metáfora ilustra bem o quanto saber falar de si autobiograficamente, ir reelaborando essas autobiografias para atribuir novos significados a si, aos outros com quem convive, aos comportamentos e atitudes, aos sentimentos e às instituições em que se está inserido contribuem para cada um/a encontrar um lugar para si 
num mundo culturalmente instituído e que necessita de constante interpretação para nos permitir "crescer".

Neste trabalho associamos a construção da identida$\mathrm{de} / \mathrm{si}$ mesmo (self) e o ensino de arte com adolescentes escolarizados no campo. Assim, partimos das seguintes questões: Qual o papel da arte na construção da identidade do/a adolescente em processo de escolarização? Como o ensino de Arte pode contribuir para o desenvolvimento das identidades de adolescentes de uma escola do campo?

O objetivo desse trabalho é compreender como a Arte influencia na (re)construção narrativa da identidade de adolescentes em processo de escolarização em uma escola do campo e está organizado em três seções, sendo que após essa Introdução, a segunda apresenta o Método de Investigação e os procedimentos utilizados para construção do corpus e da análise dos dados, o local da pesquisa, os/as participantes e na terceira seção se apresenta os resultados que foram construídos nas vivências artísticas realizadas com os adolescentes, discutindo-se esses dados à luz do referencial da Psicologia Cultural.

\section{MÉTODO}

A pesquisa se caracteriza como uma pesquisa qualitativa, na qual se utiliza o termo "trabalho de campo" como alternativa para "coleta de dados" e o pesquisador tem presença e participação constante no local da pesquisa, que pode ser com grupo de pessoas, comunidade e nesse caso em uma escola, se envolvendo e intervindo no cotidiano da vida dos sujeitos estudados (González Rey, 2009).

A pesquisa foi realizada em uma escola de ensino fundamental do campo, localizada no município de Ji-Paraná, interior do estado de Rondônia (RO) e que possui cerca de 120.000 (cento e vinte mil) habitantes, sendo a população urbana de pouco mais de 100.000 (cem mil) habitantes e uma população rural de cerca de 12.000 (doze mil) habitantes (IBGE, 2010).

A economia da região é diversificada e representada pela agricultura, pecuária, indústria (beneficiamento e transformação), extrativista (madeira, borracha, castanha do Brasil etc.), comércio e prestação de serviços (IBGE, 2010).

A escola em que foi realizada a pesquisa é de Ensino Fundamental do 1ㅇ ao 9ㅇaㅇ, da rede municipal de ensino e atendia 235 (duzentos e trinta e cinco) estudantes, com uma turma para cada ano; possuía uma equipe de 16 (dezesseis) professores/as, diretor, vice-diretor e coordenador pedagógico. A escola localiza-se a 25 (vinte e cinco) quilômetros da cidade, atendendo estudantes de diversas comunidades rurais, distantes até $30 \mathrm{~km}$ da escola em que o acesso é feito por meio de ônibus do transporte escolar da rede municipal de educação.

O primeiro contato com a instituição escolar deu- -se por meio de uma visita, na qual foi apresentada à direção da escola uma cópia do projeto aprovado pelo Comitê de Ética e Pesquisa, bem como o parecer consubstanciado de aprovação do projeto. $O$ diretor apresentou alguns professores que poderiam colaborar com a pesquisadora. Esses professores participantes da pesquisa juntamente com o diretor indicaram os/as estudantes, não havendo interferência da pesquisadora nessa escolha. Foi feito contato com os estudantes indicados e, após os esclarecimentos, os/as participantes que concordaram participar da pesquisa assinaram o Termo de Consentimento Livre e Esclarecido (TCLE), bem como os pais ou responsáveis assinaram a autorização e o TCLE.

Os/as participantes da pesquisa foram doze adolescentes matriculados no Ensino Fundamental do 6응 ao 9o ano de ambos os sexos (oito meninas e quatro meninos). Cada participante escolheu um nome fictício no primeiro encontro que o identificará nesse trabalho.

$\mathrm{Na}$ escola em que se realizou a pesquisa, a Arte aparece de várias formas: no componente curricular Arte $^{2}$ com uma aula semanal em cada turma e, como tema transversal em Língua Portuguesa e Matemática. A escola também desenvolve projetos interdisciplinares em que a Arte aparece de forma diversa, e ainda participa de outros desenvolvidos pela Secretaria Municipal de Educação. Quatro professores/as participaram da pesquisa, mas neste trabalho discutiremos dados relacionados apenas aos adolescentes.

O trabalho de campo aconteceu no contexto da escola, no qual uma pesquisadora participou do cotidiano das atividades dos adolescentes (em sala de aula e em projetos dos/as professores/as que envolvem arte no ensino e aprendizagem) e coordenou cinco encontros (mensais) no período vespertino, contra turno escolar com vivências em que a arte foi mediadora. A pesquisadora foi abordando temas por meio da Arte e registrando as ações em gravações de áudio e vídeo, sendo que a cada encontro emergiam elementos que se constituíram como pistas para o planejamento do próximo. Para o encerramento da pesquisa os participantes trouxeram os Diários Artísticos em que registraram sua participação e em duplas, iam narrando a suas experiências ali registradas, a partir de uma pergunta disparadora feita pela pesquisadora de campo, que registrou as falas em áudio.

Os dados foram analisados seguindo perspectiva proposta por González Rey (2009) e Bruner (1990/2002). Nesse trabalho foi realizada a triangulação de dados obtidos através de vários instrumentos (diário de campo

\footnotetext{
${ }^{2}$ Conforme os Parâmetros Curriculares Nacionais (Secretaria de Educação Fundamental, 1998) para o Ensino da Arte utilizase "arte" grafada com letra minúscula ao referir-se à área do conhecimento humano, e grafa-se com letra maiúscula ao referir-se à área do componente curricular.
} 
da pesquisadora, diários artísticos dos participantes, gravações em áudio e vídeo e entrevistas etc.).

\section{RESULTADOS E DISCUSSÕES}

A partir dos estudos de Bruner, pesquisas sobre a construção narrativa do self e/ou da identidade vêm se consolidando em alguns grupos de pesquisa (Vieira \& Henriques, 2014) e neste trabalho adotamos o ponto de vista da Psicologia Cultural, que admite que o self é o resultado de um processo de construção de significado:

Segundo este [...], o self não é um núcleo isolado de consciência contido em nossa cabeça, mas é construído interpessoalmente. Ele é definido em termos de significados tanto pessoal como coletivos; ambos em maior ou menor grau definidos pela cultura. Cada cultura possui uma representação do que significa pessoalidade, de modo que o significado do self é negociado entre o indivíduo e a cultura na qual ele está inserido. Nesta negociação observamos a função do kit de ferramentas de que nos fala Bruner (1987), o indivíduo constrói narrativas sobre si mesmo a partir de narrativas culturalmente dadas: tragédias, comédias, novelas, romances ou bildungsroman, nas quais ele assume o lugar de protagonista em um processo de autoconstrução. Essas narrativas possuem, portanto, uma função organizadora do self. (Vieira \& Henriques, 2014, p. 164).

Nessa mesma perspectiva, Martines e Costa (2012) trabalham com a proposta de Jerome Bruner de pensamento narrativo, que tem um papel fundamental na construção, conhecimento e ressignificação da identidade, tendo em vista sua alta capacidade de organização da experiência vivida, que se revela na forma de histórias ou narrativas, as quais são construções mentais repletas de atos de significação. Isso implica dizer que as histórias de vida são passíveis de constantes interpretações e reinterpretações do mundo e de si mesmo, porém, alertam que essa proposta ainda é pouco estudada e compreendida, no âmbito da Psicologia. De acordo com essa concepção, foram apresentados vários objetos culturais $^{3}$ aos sujeitos adolescentes na forma de vivências artísticas, conforme descrito a seguir.

\section{As vivências artísticas}

Bruner (1990/2002) defende que os seres humanos constroem significados a partir dos sistemas simbólicos já dados na cultura, os quais constituem uma espécie de kit de ferramentas que os homens utilizam para construir suas representações do mundo, sendo que a narrativa é uma dessas ferramentas: "[...] meu ponto de vista em relação à narrativa é construtivista - uma visão que tem como premissa que a principal função da mente é a construção do mundo, quer seja através das

\footnotetext{
${ }^{3}$ Informações sobre esses podem ser encontrados na dissertação que deu origem a este trabalho (Azevedo, 2015).
}

ciências ou das artes". (Bruner, 1987, p. 11).

O primeiro encontro com os participantes desta pesquisa intitulou-se "Vivência artística dos nomes" e se iniciou com o jogo teatral "Batizado Mineiro" de Augusto Boal (Boal, 1998; Silva, 2016), com os/as participantes em círculo; foi perceptível a timidez, vergonha, "tiração"4 , curiosidade e, nesse caso, a vivência foi importante para que os/as participantes fossem se tornando mais confiantes, expressivos, desinibidos.

Após todos se apresentarem, iniciou-se uma conversa sobre o que nos identifica e foram citadas a certidão de nascimento e a cédula de identidade (RG) que identifica uma pessoa com: nome, data e local de nascimento, filiação, data de emissão, foto, impressão digital do polegar direito e assinatura.

Conversou-se sobre o que é necessário para uma pessoa existir civilmente no Brasil, a obrigatoriedade de ter a certidão de nascimento e cédula de identidade (documento nacional de identificação civil) e que toda pessoa para se apresentar como cidadão precisa ter esses documentos. Outro assunto que surgiu nesse diálogo foi sobre o estado civil e que quando acontece a mudança de estado civil de solteiro(a) para casado(a), muda-se a certidão de nascimento para a certidão de casamento. Nessa roda de conversa os/as participantes puderam perceber a importância de fazerem a carteira de identidade, já que apenas dois adolescentes a possuíam.

A seguir, a pesquisadora questionou: "Quem sou eu?" e juntos assistiram ao vídeo com a música: "Gente tem sobrenome" de Toquinho (Pecci Filho \& Andreato, 2002), seguido de conversa sobre os personagens que apareceram na música, sendo que alguns foram identificados pelos participantes. Para contextualizar historicamente a música, foram mostradas imagens do compositor e seus amigos da época: Toquinho, Vinícius de Moraes e Tom Jobim.

Na sequência, fez-se a apreciação do vídeo com imagens e poema de Pedro Bandeira "O nome da gente" (Bandeira, 1984). No poema o autor apresenta de forma poética e lúdica a ideia de a pessoa não gostar do seu nome, de não ter sido a pessoa quem o escolheu, fala do neném que vai nascer e que vai se chamar igual ao padrinho, ao vovô, enfim todos interferem na escolha desse nome e ninguém pergunta ao bebê como ele gostaria de ser chamado. Ao final, o poeta satiriza dizendo que quando tiver um filho vai deixar livre para que ele escolha o seu nome somente quando crescer.

O momento descontraído após o vídeo permitiu uma reflexão e discussão sobre o nome de cada participante, se é possível uma pessoa ficar sem um nome até crescer, com as seguintes questões: Quem escolheu o seu nome?

\footnotetext{
${ }^{4}$ Tiração: termo utilizado entre os adolescentes para zoar, tirar sarro um do outro.
} 
O que você sabe sobre o seu nome? Qual o significado do seu nome? Essa última gerou uma pesquisa na Internet com uso do Uquinha, o laptop pessoal, pois a escola foi uma das oito escolas-piloto do Projeto UCA (Um Computador por Aluno) (Martines et al., 2012).

Conversou-se sobre a necessidade de um nome fictício que seria de livre escolha de cada um para ser usado na pesquisa. Imediatamente alguns escolheram os nomes que um dos pais ou que os/as avós tinham escolhido; outros escolheram nomes de jogadores de futebol ou de personagens conhecidos através do cinema ou televisão, constituindo um momento de realizarem as vontades que não foram satisfeitas em relação aos seus nomes. Cada participante recebeu um caderno grande de desenho que denominamos de "Diário Artístico", a fim de colocarem seus sonhos, medos, revoltas, expectativas, vivências e sentimentos artisticamente, isto é, em forma de poesia, música, pinturas, informações sobre filmes, fotografias, imagens etc.

No Diário Artístico cada participante colocou o seu nome e o nome fictício; na segunda página a fotocópia da certidão de nascimento; na terceira página a letra da música "Gente tem sobrenome" e da poesia "O nome da gente"; na quarta página o resultado da pesquisa realizada com os pais sobre sua chegada ao mundo, origem e significado do nome; a partir da quinta página ficaram livres para expressar por meio da arte suas emoções e sentimentos experimentados durante a pesquisa.

O encontro foi encerrado com a música "A paz" de Thelma Chan $^{5}$ em que cada participante se abraça e depois abraça os demais. Na primeira vez que se cantou, alguns adolescentes apresentaram um pouco de resistência para abraçar, aparentando desconforto em tocar o colega, mas ao final fez-se um grande abraço em círculo.

O segundo encontro teve como tema "Autorretrato - Identidade/noção de si mesmo" e se iniciou com as considerações sobre a origem do gênero artístico "Autorretrato", desde o tempo em que não existia máquina fotográfica e as pessoas eram retratadas por artistas (com um custo alto) até o presente em que dispomos de recursos tecnológicos popularizados para fotos, as selfies. Por isso, atualmente o autorretrato tem um caráter mais artístico. A seguir foram projetados os Vídeos: "Projeto Autorretrato", "Identidade e Autorretrato" e "Autorretrato", preparando os adolescentes para o desafio de se autorretratarem com materiais diversos a partir dos seguintes questionamentos: Como eu me vejo? Como os outros me veem? Como vejo minha própria história? O que nos identifica fisicamente? Cor da pele, tipo de cabelo, expressões faciais, estatura etc.?

Os adolescentes utilizaram o laptop UCA para tirar

\footnotetext{
${ }_{5}^{5}$ Thelma Chan. A paz. Disponível em http://www.thelmachan. com.br/download/15\%20A\%20Paz.mp3. Acessado em $10 / 07 / 2014$.
}

uma foto (selfie) que pudesse servir de base na confecção do autorretrato, sem a preocupação do que é belo ou feio, não se prendendo na foto, o que facilitou suas produções. O clima foi de muita descontração ao som de músicas diversas. As produções foram executadas no Diário Artístico com canetas hidrocor, lápis de cor ou lápis preto. Para o encontro seguinte, solicitou-se que fizessem uma contextualização histórica do ano em que nasceram, pesquisando sobre acontecimentos importantes no mundo, país, Estado, cidade e família.

O terceiro encontro foi intitulado de Vivência Artística "Conhecendo a si mesmo" e se iniciou com uma roda de conversa sobre os resultados da pesquisa a respeito de acontecimentos interessantes no ano de nascimento. A maioria dos/as participantes nasceu entre 2000 e 2002, época em que o país viveu a expectativa de ser pentacampeão do mundo no futebol, o que de fato aconteceu em 2002. Os pais e/ou responsáveis lembraram-se desses fatos e os adolescentes contaram com muito entusiasmo e orgulho de terem nascido na época em que o Brasil foi pentacampeão mundial no futebol.

Na abordagem da Psicologia Cultural, admite-se que "o sucesso e o fracasso são os principais nutrientes da selfhood" humana (Bruner, 2001, p. 41), a qual se caracteriza pela:

[...] construção de um sistema conceitual que organiza [...] um "registro" de encontros como agentes com um mundo, um registro que está relacionado ao passado (ou seja, a chamada "memória autobiográfica"), mas que também extrapola para o futuro - um self com história e possibilidade. Trata-se de um self possível que regula a aspiração, a confiança, o otimismo e os seus opostos. Embora este sistema do self construído seja interno, privado e repleto de afeto, ele também se estende para fora, em direção às coisas, atividades e lugares com os quais nos tornamos "envolvidos com o ego" - o self expandido de William James. As escolas e a aprendizagem escolar estão entre estes primeiros lugares e atividades. (grifo nosso) (Bruner, 1996/2001, p. 41).

Castelo Branco (2003) argumenta que não é possível estudar a identidade fora das relações sociais e devemos sempre remetê-la a situações concretas de vida, a grupos e indivíduos em atividade, uma vez que a identidade pessoal se produz dentro de um processo de múltiplas identificações sociais, em relações que colocam em encontros e confrontos o "eu", o "nós" e "eles" e que não implica meramente a busca de semeIhanças e diferenças.

\footnotetext{
${ }^{6}$ A singularidade humana, uma autoconsciência com reconhecimento das outras autoconsciências.
} 
Segundo essa corrente de pensamento, a identidade ou a noção de si mesmo é construída dentro de um contexto histórico-cultural, por meio de interações sociais. No caso dos povos do campo, como é o caso dos participantes dessa pesquisa, a construção da identidade pode vir carregada de preconceitos e estereótipos, como o estereótipo do caipira, que foi por tanto tempo reproduzido e legitimado nos discursos literários e de livros didáticos, que tentam inferiorizar e descaracterizar essa população (Carvalho, 2011; Castelo Branco, 2003).

Nas discussões sobre a escolha dos nomes, os adolescentes disseram:

Foi meu pai que estava assistindo um filme uma vez, e tinha um personagem com esse nome, então ele disse que quando tivesse um filho iria colocar esse nome. Minha mãe nem sabia falar meu nome. [...] (Roberto, 12 anos).

Meu nome foi meu pai que escolheu, vem de um papel que o astro de cinema Nicolas Cage fez. (Diego, 12 anos).

Não sei por que escolheram esse nome, não sei nada sobre eu. (Luíza, 13 anos).

A única coisa que sei falar do meu nome é que foi minha irmã que escolheu, minha mãe gostou, meu pai também. Eu não escolheria outro nome, estou satisfeita com o meu. (Jhorrana, 12 anos).

Eu odeio esse nome, sabe assim..., não bate comigo, sei lá... Eu não queria esse nome. Se eu fosse escolher seria Cristina ou Clarice que nem minha avó [queria]. (Lucrécia, 14 anos).

Nessas pequenas narrativas, existe uma mistura de fatos envolvidos na escolha dos nomes dos/as participantes com sentimentos, sendo que a arte cinematográfica e os meios de comunicação aparecem influenciando a escolha de nomes dos/as filhos/as; a interferência de familiares sugerindo nomes; questões religiosas, seja de nomes de personagens bíblicos bem como de promessas realizadas pelos genitores e familiares, ou por ter nascido no dia de determinado santo.

Diante de tantas intervenções na escolha do nome, encontramos no grupo, participantes que não gostam do seu nome e que se pudessem, escolheriam outro. Entre os meninos foi forte a opção do nome artístico por nomes de jogadores de futebol, até mesmo pelo momento que o país estava vivendo de recepcionar a copa do mundo.

Quem escolheu meu nome foi meu pai, porque o avô dele e o bisavô também têm o meu nome, meu nome artístico será Balotelli. (Balotelli, 13 anos).

Meu primeiro nome é de origem inglesa, o sobrenome de origem indígena. Eu vim por acaso. Minha mãe, primeiro teve minha irmã, ela falou que queria um casal, só que antes da minha irmã ela teve um filho que morreu, então ela teve eu depois, eu vim de intruso, mas ela gostou porque ficou com um casal. (Neymar, 13 anos).

$O$ adolescente Neymar explica a origem do seu nome e sobrenome, e acrescenta algo que não foi solicitado ao grupo, que é o fato de ter vindo sem planejamento do casal. Outros comentários sobre o não planejamento da gestação surgiram na roda de conversa em que cada participante se apresentava: "Eu também nasci por acaso. Já meu irmão foi planejado, ele tem três anos." (Davi Luiz, 12 anos). "[...] eu não fui assim um plano deles realmente, eu não fui planejada, minha mãe me teve muito nova e meu pai era mais velho..." (Patrícia, 14 anos).

Falar e refletir a respeito do nome e sobrenome incitaram situações que não foram previstas durante o planejamento da vivência, entretanto fomos percebendo que para esses/as adolescentes eram fatos que faziam parte da sua identidade, da maneira como se viam como pessoa, era a constituição do self em andamento, situações nas quais o significado de quem eram estava em construção.

No terceiro encontro realizou-se ainda a "Vivência do espelho" e este foi um momento marcante: os participantes foram ficando silenciosos e alguns adolescentes que apresentavam muita dificuldade para se concentrar no decorrer das vivências ficaram impactados com a própria imagem refletida no espelho colocado dentro de uma caixa de modo que os demais não pudessem ver o que havia na caixa. Muitos choravam ao voltar silenciosamente para seu lugar, continuando a reflexão sem se comunicar com os demais.

Uma roda de conversa encerrou essa vivência para que os participantes compartilhassem seus sentimentos, suas reflexões e conclusões sobre essa pessoa tão especial que viram refletida no espelho, com o seguinte questionamento: Será que é possível a gente amar o outro se a gente não se amar primeiro?

Aproveitando o clima de reflexão, e por se ter percebido no primeiro encontro que existe certo preconceito racial com relação a alguns participantes que são negros, foi planejada a apreciação do vídeo "Menina bonita do laço de fita" baseado no livro literário infantil de Ana Maria Machado, com ilustrações e narrativa de uma linda menina negra que usava trancinhas coloridas feitas pela mãe.

Após assistir o vídeo, foi-se questionando e ouvindo os adolescentes a respeito do tema racismo: "Você já parou para pensar com quem se parece? Com seus avós, pais? Em nossa família, todos são de uma cor só? Como seria se todos fossem da mesma cor e iguais, com as mesmas características físicas? 0 que nos faz pensar: esta pessoa é bonita, esta é feia? Qual a aparência que os programas de televisão, as novelas e os meios de 
comunicação em geral mostram que é a mais bonita? Em nosso país existe preconceito? Mesmo com tantas leis a respeito do racismo, existe preconceito? E aqui na escola, existe preconceito? Será que nossas brincadeiras não estão carregadas de preconceito? Quando alguém diz "Você é preto", essa pessoa quer elevar ou inferiorizar o outro? O que aconteceu com os negros no Brasil?".

Após um tempo em que todos puderam se manifestar com reflexões sobre esses questionamentos, foi apresentado o vídeo em curta metragem Vista a minha pele e foi solicitado que os participantes se colocassem no lugar de outra pessoa, daquele que é discriminado, que é visto como diferente.

Finalizou-se essa vivência com referência ao Dia Internacional de Nelson Mandela (que se comemorou naquela semana): um pouco da história desse grande líder africano e sua famosa frase: "Ninguém nasce odiando outra pessoa pela cor da sua pele, por sua origem ou ainda por sua religião. Para odiar as pessoas precisam aprender, e se podem aprender a odiar, podem ser ensinadas a amar." (Mandela et al., 20057).

A aluna Silvana, que é negra e sempre se apresentou muito tímida durante os outros encontros, pela primeira vez participou da discussão e disse: "Ah, professora, todos deveriam ser iguais". A pesquisadora-mediadora ressaltou que somos diferentes, mas que deveríamos sim, ter as mesmas oportunidades, chamando a atenção para o pai da menina negra do filme que representava a burguesia branca na inversão do filme quando ele disse: No Brasil todos tem a mesma oportunidade, cada um tem que lutar pelos seus direitos e aqueles que batalham vencem. A pesquisadora-mediadora perguntou: "Será que no Brasil todos têm as mesmas oportunidades?", seguindo-se uma discussão sobre a pergunta.

Em seguida, passou-se para um momento de produção artística, em que escreveram a frase de Nelson Mandela no diário artístico, escolheram uma imagem das revistas disponibilizadas na sala, que para eles representasse essa frase e colaram no diário.

A etapa seguinte foi intitulada de "Vivência Sessão cinema 'Escritores da liberdade ${ }^{8 \prime \prime \prime}$, onde se destacou os elementos básicos da arte cinematográfica, tais como: Cena, sequência, ato, personagem, diálogo, roteiro, gênero, duração, direção, trilha sonora etc. Conversamos um pouco sobre os bastidores do filme Escritores da Liberdade, curiosidades interessantes que fazem toda a diferença no momento de apreciação de um filme baseado em uma história verídica.

Quand o o filme terminou foram mostradas imagens

\footnotetext{
${ }^{7}$ Frase recuperada em https://www.pensador.com/frase/ MzM1Njlw/.

${ }^{8}$ Escritores da liberdade, filme lançado em 2007 com direção de Richard Lagravenese, drama, 123 minutos. EUA: Paramount Pictures.
}

dos personagens da vida real que viveram essa história e sobre a fundação que esse grupo montou para que outras salas de aula parecidas com a que foi retratada no filme fossem implantadas.

No quinto encontro realizou-se a Vivência artística "A música na construção da identidade/si mesmo do adolescente" para a qual foi preparado um banco de dados com videoclipes das músicas escolhidas pelos participantes e as letras em Power Point. Foi um momento bem descontraído, no qual também ficou estabelecido que se teria respeito pelo gosto musical de cada participante dando abertura para a diversidade musical no grupo, enfatizando os elementos da linguagem musical, tais como: ritmo, melodia, harmonia, letra, andamento, estilo musical.

As músicas escolhidas pelos participantes tinham diferentes estilos: música sertaneja (Duas Metades; Bebeu, fudeu); gospel (Abrigado em Jesus, Ele é a minha Iuz, Adore a Ele); dançante (Soy rebelde; I'm glad you came [Fico feliz que você veio]); romântica (Ninguém vai sonhar; Eduardo e Mônica; Força Estranha). Refletiu-se sobre os diversos tipos de música e de sua importância, em virtude de sermos seres com vivências diversas, experimentamos sentimentos variados que são difíceis de serem traduzidos em palavras e que em todo o ciclo de nossa vida existe música, desde o nascimento até a morte. Ela está presente em todos os nossos relacionamentos, seja de amizade, de amor, de louvor a Deus, enfim, ela faz parte de toda nossa existência. Ao final, percebeu-se que uma adolescente que havia escolhido a música religiosa e que estava um pouco tímida, ficou mais à vontade com toda essa reflexão a respeito de uma música para cada circunstância da nossa vida.

Assim, como Bruner (1990/2002) concluiu em pesquisa realizada por ele e uma colaboradora, que: "Tornou-se logo tão evidente não apenas que a vida imita a arte, mas que ela o faz escolhendo como modos de expressão gêneros artísticos e outros dispositivos de narração de histórias" (p. 104), também identificamos diferentes gêneros musicais e narrativos influenciando a construção das identidades daqueles adolescentes.

Finalizou-se com a vivência de uma viagem musical, na qual os participantes fecharam os olhos, ficaram deitados, relaxados, ao som de música instrumental para reflexão. Cada participante fez a sua viagem e foi estimulado a ficar em silêncio, se desconectar um pouco das coisas ao redor e olhar para dentro de si mesmo, para depois olhar também para as pessoas à sua volta, com as quais convivem, pois é fundamental valorizar os relacionamentos, as pessoas que amamos e com as quais convivemos.

Ao final da "viagem", pediu-se para que cada participante desenhasse em um papel o que vivenciou, quem encontrou e que fizesse isso em silêncio. Ao final, sentados no chão, compartilhou-se a experiência em 
uma roda de conversa.

Entendemos como um papel da escola a estimulação de uma escuta sensível, desenvolvendo a fruição e a produção artística, desfrutando da diversidade de músicas, obras de arte, teatro, dança que fazem parte do patrimônio da humanidade e são poderosos instrumentos interpretativos, ao lado do desenvolvimento dos conceitos científicos (pensamento paradigmático). Todos esses aspectos mobilizam o indivíduo a transcender as restrições da mente humana, da linguagem e da cultura, para aumentar a compreensão de si mesmo e da realidade, assumindo seu lugar no mundo como agentes mais conscientes e capazes de transformar (a si mesmo e a esta "Realidade") diante dos mundos possíveis disponibilizados pela cultura na qual este indivíduo está inserido.

\section{CONSIDERAÇÕES FINAIS}

Dentro da perspectiva da Psicologia Cultural, a identidade/noção de si-mesmo (self) se constrói nas relações vivenciadas ao longo da existência humana, com os outros si-mesmos (selves), desde a gestação mediante as expectativas dos genitores em relação ao novo ser que está sendo gerado, no nascimento, na infância, na adolescência e assim por todo o percurso da vida dentro da cultura em que esse indivíduo está inserido.

A concepção de adolescência adotada nessa pesquisa considera esta fase do desenvolvimento situada dentro de uma cultura, ou seja, que se constrói nas relações estabelecidas no processo cultural, histórico e social de uma sociedade; um período de crise de identidade e de transição, no qual surge o pensamento abstrato, a formação de conceitos científicos, de ascensão da imaginação, bem como o desenvolvimento de outras funções psicológicas superiores.

Sendo a adolescência um período em que a fantasia, uma das manifestações da atividade criadora, está em potente ascensão e a imaginação está relacionada ao pensamento por conceitos (pensamento abstrato), na qual os interesses infantis são modificados, é fundamental atentar para o desenvolvimento dos processos criativos do/a adolescente e o desenvolvimento de habilidades interpretativas, ampliando assim a compreensão de si mesmo e do mundo desses seres em transição.

Em cada encontro as vivências artísticas provocaram a emergência de narrativas que estavam silenciadas trazendo-as à tona; fatos e sentimentos que desde a infância incomodavam esses/as adolescentes tornaram-se conscientes e puderam ser refletidos com a interação ocorrida nas vivências, o que ajudou cada um a ressignificar relacionamentos e a noção que tinham de si mesmo e dos outros.

Diante dessa experiência em grupo, a arte foi se revelando como uma ferramenta mediadora nas provocações, discussões e reflexões de como o/a adolescente se vê, o que ele/a sabe sobre si mesmo/a e permitiu constatar que é possível trabalhar temas que estão latentes no dia a dia do contexto escolar, gerando muitos problemas de comportamento, de relacionamento, de baixo desempenho acadêmico, de autoestima baixa e agressividade ${ }^{9}$, os quais são fundamentais para a construção da identidade do/a adolescente e que nem sempre a escola está preparada para abordá-los.

Com a interpretação dos vários signos contidos nas produções artísticas, as vivências contribuíram para a apropriação de instrumentos psicológicos importantes para lidar com emoções, sentimentos, pensamentos, refletindo-se no desenvolvimento de funções psicológicas superiores.

A arte possibilitou ao/a adolescente repensar e (re) construir narrativas sobre sua vida, sua existência, seu self, como vieram ao mundo, suas contradições, suas perdas, amor e ódio relacionados ao abandono do pai, ciúmes dos irmãos, preconceitos etc., oportunizando a reflexão e ressignificação de sua identidade/noção de si mesmo/a.

Nessas vivências artísticas, a arte em suas diversas linguagens: música, poesia, cinema, artes visuais, desenho, além do seu efeito de experiência estética de fruição, despertou, provocou e suscitou nesses/as adolescentes emoções e sentimentos contrastantes, e ao viverem essa experiência de catarse possibilitou por meio do pensamento em conceitos e abstrações, uma ampliação do conhecimento de si mesmo, do outro e do mundo.

Reconhecer a arte como técnica social do sentimento (Vigotski ${ }^{10}$, 1999) auxilia a formação do novo homem, de um homem que se constrói coletivamente, que expressa artisticamente o conjunto das representações da cultura em que vive, suas crenças, valores, situação econômica, classe social, religiosidade, enfim, a realidade que vive cotidianamente.

A Psicologia Cultural proposta por Bruner (2001; 2002) defende que a cultura fornece muitos modelos ou formas de identidade e modos de vida por meio da arte e nessa pesquisa, procuramos introduzir elementos da cultura artística que pudessem levar os adolescentes a se tornarem mais conscientes de suas identidades e a reconfigurá-las com auxílio de recursos artísticos, introduzindo novos modelos, os quais dificilmente lhes seriam apresentados em seus ambientes familiares e culturais, na dura realidade do campo no Brasil.

\footnotetext{
${ }^{9}$ No final da pesquisa, verificamos que os participantes foram indicados pelos professores por apresentarem estes problemas.

${ }^{10}$ Algumas obras deste autor foram publicadas em português com a grafia Vygotsky outras como Vigotski e nesse trabalho optamos pela grafia com $i$, com exceção das citações, as quais seguem a opção do tradutor.
} 
Considerando o ineditismo dessa pesquisa e a riqueza de dados, sugerimos que pesquisas futuras sejam efetuadas em outros contextos culturais (escolas da cidade, periferias, de populações vulneráveis ou não) ou mesmo em outras escolas do campo para fins de comparação e identificação de singularidades próprias de cada contexto.

Quanto ao método, seria interessante também uma diversificação, como por exemplo, a realização de pesquisas-ação relacionadas com a formação de professores. Em nosso caso, quatro professores da escola participaram do estudo, sendo que a professora de Artes e a professora de Língua Portuguesa participaram de todas as vivências e relataram que aprenderam muito, se justificaram quanto à sua formação e afirmaram que notaram mudanças pessoais e relacionais nos participantes da pesquisa.

Infelizmente, por questões de mudanças pessoais das pesquisadoras envolvidas, não houve possibilidade de continuidade da pesquisa nem desenvolvimento de outras intervenções extensionistas. No entanto, fizemos uma visita à escola e entregamos uma cópia da dissertação que originou este trabalho aos estudantes participantes (que fizeram questão de manuseá-la procurando suas produções), professores participantes e gestor, a qual pode ser usada para melhor compreensão da crise de identidade adolescente e da importância da escola e da atuação de professores no cotidiano escolar para a superação positiva desta crise com auxílio das várias manifestações artísticas disponíveis na cultura local e na universal, seja através da fruição e reflexão, seja através da produção.

Destaque-se, inclusive, o belo trabalho realizado por dois professores da referida escola (Língua Portuguesa e Matemática) que participaram da pesquisa por utilizarem recursos artísticos em suas disciplinas como tema transversal e pelo envolvimento de toda a comunidade escolar na realização de eventos com produção artística, conforme descrito por Azevedo (2015).

Para pesquisas futuras inspiradas nessa obra sugerimos que os autores levem em consideração a possibilidade de outras formas de retorno para a escola, tais como pesquisa-ação, projetos de extensão para formação continuada de professores com reflexão sobre a crise de adolescência.

De modo geral, entendemos que os objetivos da pesquisa foram alcançados, uma vez que se observou que os resultados apresentados pelos participantes evidenciam melhora na sua autoestima e na alteridade, com a ampliação do conhecimento de si mesmos e do outro, reconfiguração de relações interpessoais com mais respeito uns pelos outros no cotidiano escolar e até melhora no desempenho escolar, segundo relatos dos gestores e professores desses adolescentes.

\section{REFERÊNCIAS}

Azevedo, S. R. S. (2015). A arte na construção da identidade: um estudo com adolescentes e professores de uma escola do campo em Rondônia (Dissertação de Mestrado). Universidade Federal de Rondônia (UNIR), Porto Velho. Recuperado de http://www.mapsi.unir.br/pagina/ exibir/4873

Bandeira, P. (1984). O nome da gente. In Cavalgando o arcoíris. São Paulo: Moderna.

Boal, A. (1998). Jogos e exercícios do teatro do oprimido. Rio de Janeiro: Civilização Brasileira.

Brasil. Ministério de Educação. Secretaria de Educação Fundamental. (1998). Parâmetros Curriculares Nacionais: Arte Ensino de quinta à oitava série. Brasília: MEC/SEF.

Bruner, J. (1987). Life as narrative. Social Research, 54 (1), 11-32.

Bruner, J. S. (2001). A Cultura da Educação (2ª ed., M. A. G. Domingues, Trad.). Porto Alegre: ArtMed Editora. (Trabalho original publicado em 1996).

Bruner, J. S. (2002). Atos de Significação (S. Costa, Trad.). Porto Alegre: Artes Médicas. (Trabalho original publicado em 1990).

Carvalho, R. A. (2011). A construção da identidade e da cultura dos povos do campo, entre o preconceito e a resistência: o papel da educação (Tese de Doutorado). Educação da Universidade Metodista de Piracicaba - UNIMEP, Piracicaba, SP. Recuperado de http://www.gepec.ufscar.br/ publicacoes/tccs-dissertacoes-e-teses/tese/a-construcaoda-identidade-e-da-cultura-dos-povos.pdf/view

Castelo Branco, M. T. (2003). Jovens sem-terra: Identidades em movimento. Curitiba: Ed. da UFPR. 176p.

González Rey, F. L. (2009). O enfoque histórico-cultural e seu sentido para a psicologia clínica. In: A. M. B. Bock; M. G. M. Gonçalves; O. Furtado (Eds.), Psicologia Sócio-Histórica: uma perspectiva crítica em psicologia (4a ed, pp. 193-214). São Paulo: Cortez.

IBGE. (2010). Censo 2010. IBGE Cidades: Ji-Paraná/ População. Recuperado em 13 de novembro de 2013, de http://www.ibge.gov.br/cidadesat/painel/painel. php?codmun=110012\#.

Mandela, N.; Boatman, M. (Read by); Gelman, S. (2005). Long Walk to Freedom: The Autobiography of Nelson Mandela [Audio]. Little Brown and Company.

Martines, E. A. L. de M. e Costa, M. F. da. (2012). Memórias amazônicas e a identidade autobiográfica da Menina-dorio. Anais do VI Simpósio Linguagens e Identidades da/ na Amazônia Sul-Ocidental / Colóquio Internacional "As Amazônias, a África e as Áfricas na Pan-Amazônia?. Rio Branco / AC. Anais... 05 a 09/11/2012.

Pecci Filho, A. e Andreato, E. V. (compositores). (2002). Gente tem sobrenome (música). In Canção de todas as crianças. Tonga Ed. Musical Ltda.

Silva, C. D. da. (2016). Diálogos pedagógicos: o Teatro do 
Oprimido e a política de educação integral no município de Ipatinga - MG. (Trabalho de Conclusão de Curso) Licenciatura em Teatro do Departamento de Artes Cênicas do Instituto de Artes da Universidade de Brasília (UnB). Brasília / DF.

Souza, S. R.; Martines, E. A. L. M.; Barroco, S. M. S. (2018). Ensino de arte e os processos criativos na adolescência. Rev. Educação, Artes \& Inclusão, 14(3), 234- 262. Recuperado de http://dx.doi.org/10.5965/1984317814032018234.
Vieira, A. G.; Henriques, M. R. (2014). A Construção Narrativa da Identidade. Psicologia: Reflexão e Crítica, 27(1), 163170.

Vygotsky, L. S. (2001). A Construção do Pensamento e da Linguagem. (P. Bezerra, Trad.). São Paulo: Martins Fontes. Trabalho original publicado em 1934.

Vigotski, L. S. (1999). Psicologia da arte (P. Bezerra, Trad.). São Paulo: Martins Fontes. Trabalho original publicado em 1925.

Agradecemos a colaboração do gestor, professores e estudantes da Escola Municipal de Ensino Fundamental Prof. Irineu Dresch de Ji-Paraná / RO no desenvolvimento das oficinas de arte com adolescentes. Trabalho derivado de dissertação defendida no Mestrado de Psicologia da UNIR, após aprovação do Comitê de Ética em Pesquisa da Universidade Federal de Rondônia pelo parecer no 650.839 .

Recebido: 20 de junho de 2019 Aprovado: 08 de maio de 2020 